\title{
ADAMTS12 Depletion by Insulin in OUMS-27 Human Chondrosarcoma Cells
}

\author{
Aynur ALTUNTAŞ, ${ }^{1}$ Sümeyya AKYOL, ${ }^{2}$ Bahattin ADAM, ${ }^{3}$ Özlem ÇAKMAK, ${ }^{4}$ Veli UĞURCU, ${ }^{5}$ \\ Gönül ERDEN, ${ }^{6}$ Yunus YÜKSELTEN, ${ }^{7}$ Kadir DEMİRCAN ${ }^{2}$ \\ ${ }^{1}$ Department of Chemistry, Ankara Regional Office of Council of Forensic Medicine, Ankara, Turkey \\ ${ }^{2}$ Department of Medical Biology, Medical Faculty of Turgut Özal University, Ankara, Turkey \\ ${ }^{3}$ Department of Medical Biochemistry, Mevlana University Medical School, Konya, Turkey; San Jose State University, \\ San Jose, California, USA \\ ${ }^{4}$ Department of Biology Education, Gazi University, Faculty of Education, Ankara, Turkey \\ ${ }^{5}$ Department of Medical Biochemistry, Dumlupinar University Medical Faculty, Kutahya, Turkey \\ ${ }^{6}$ Department of Medical Biochemistry, Hacettepe University Medical School, Ankara, Turkey \\ ${ }^{7}$ Department of Medical Biology, Medical Faculty of Ankara University, Ankara, Turkey
}

\begin{abstract}
Objectives: In this study, we aim to investigate the association between articular damage in diabetes and a disintegrin-like and metalloproteinase with thrombospondin motifs 12 (ADAMTS12) at gene expression and protein levels.

Materials and methods: OUMS-27 human chondrosarcoma cells were used to investigate how ADAMTS12 levels changed in vitro condition in presence and absence of insulin. The study included three groups of cells treated with $10 \mu \mathrm{g} / \mathrm{mL}$ of insulin, and a control group. Cells were incubated with insulin in medium for one day, three days, and seven days. The effects of insulin on ADAMTS12 were investigated at both gene expression and protein levels. The relationships between the variables were tested by Mann-Whitney $\mathrm{U}$ test.

Results: ADAMTS12 expression was significantly lower in the groups treated with insulin medium for one day and seven day periods ( $p=0.008$ and $p=0.008$, respectively) compared to the control group. No significant difference was detected in the expression level between the groups kept in insulin medium for three days and the control group ( $p=0.55$ ). In addition, protein amounts of the groups exposed to insulin medium for one, three, and seven day periods were lower.

Conclusion: Insulin reduces the amount of ADAMTS12 which causes delayed recovery of cartilage tissue in the OUMS-27 cell lines utilized in our study for their chondrocytic properties. This reduction due to insulin treatment may contribute to recovery of cartilage tissue.

Keywords: ADAMTS12; cartilage tissue; insulin; OUMS-27.
\end{abstract}

Progressive joint destruction is an important criterion in predicting long-term progression of rheumatoid arthritis and osteoarthritis. Despite improved treatment and care options, prevention of joint destruction may be quite difficult. ${ }^{1}$ The pathophysiology of arthritic joint destruction involves proteolytic breakdown of cartilage tissue. Particularly, aggrecan breakdown in extracellular matrix results in joint destruction. ${ }^{2,3}$ Matrix metalloproteinases and a disintegrin and metalloproteinase with thrombospondin motifs (ADAMTS) play role in cartilage breakdown. ${ }^{4}$ ADAMTSs belong to metzincin superfamily of metalloendopeptidases, and involve more than 19 distinct genes. ${ }^{5}$ ADAMTS gene products have protease activity. ADAMTS1, $-4,-5,-8$, -9 and -15 have aggrecanase activity whereas other members do not. ${ }^{2}$ The cartilage tissue of the patients with osteoarthritis and rheumatoid arthritis include biglycan fragments obtained due 
to breakdown of proteoglycans by ADAMTSs. ${ }^{6}$ On the other hand, distinct ADAMTS genes play role in etiopathology of different disorders. ADAMTS genes are upregulated in some disorders while they are downregulated in others.

A disintegrin-like and metalloproteinase with thrombospondin motifs 12 has been first reported by Cal et al. ${ }^{7}$ in 2001. ADAMTS12 gene is found in skeletal muscles, cartilage, tendons and fetal lung. ${ }^{7-9}$ ADAMTS12 was shown to be associated with arthritis, ${ }^{10}$ intervertebral disc degeneration, ${ }^{11,12}$ inflammation, ${ }^{13,14}$ tumor invasion, and metastasis. ${ }^{15-17}$ Also, high levels of ADAMTS12 messenger ribonucleic acid (mRNA) were detected in osteoarthritis and rheumatoid arthritis. ${ }^{18,19}$ On the other hand, role of ADAMTS12 in articular cartilage, and regulation and biochemistry of ADAMTS12 at gene level have not been clearly demonstrated.

Insulin increases synthesis of mucopolysaccharides in the chondrocytes whereas it elevates synthesis of proteoglycans in the tumor cells obtained from the chondrosarcoma cells. In other respects, insulin causes a positive nitrogen balance by elevating amino acid uptake. ${ }^{20,21}$ Insulin binds to receptors of insulin-like growth factor 1 (IGF-1) at high concentrations such as $10 \mu \mathrm{g} / \mathrm{mL}$, and imitates its effect in cartilage tissue. ${ }^{22}$ When used at dosages below $10 \mathrm{nmol} / \mathrm{L}$, it causes an increased matrix synthesis while preventing matrix breakdown by inhibiting aggrecanase activity and harmful effects of nitric oxide and interleukin-1 (IL-1) on cartilage tissue. ${ }^{23}$ Exact opposite events occur in diabetes due to insulin deficiency and hyperglycemia. Degraded structural integrity of the articular cartilage and proteoglycan changes in the intervertebral discs are common in diabetic patients. Elevated cartilage loss and delayed bone fracture healing may also occur. ${ }^{24-26}$ Despite investigations, the degradation mechanism of the articular cartilage has not been clearly shown.

In this study, we aimed to investigate the association between articular damage in diabetes and ADAMTS12 at gene expression and protein levels. We investigated how ADAMTS12 levels changed in vitro in presence and absence of insulin. OUMS-27 cell lines that have been established from chondrosarcoma cells and express chondrocytic properties are used in investigating pathophysiology of cartilage disorders due to the difficulties in obtaining chondrocytes. OUMS-27 cell line secretes cartilage-specific proteoglycans, and type- 2 and -9 collagens. ${ }^{27}$ We used OUMS-27 cell line in our study as well.

\section{MATERIALS AND METHODS}

OUMS-27 human chondrosarcoma cells were kindly provided by Dr. T. Kunisada from Okayama University Graduate School of Medicine and Dentistry, Okayama, Japan. Cells were cultured in Dulbecco's modified Eagle's medium containing $10 \%$ fetal bovine serum and penicillin/streptomycin at $37^{\circ} \mathrm{C}$ in a humidified atmosphere of $5 \% \mathrm{CO}_{2}$ in air. The cells were subcultured at split ratios of 1:21:4 using trypsin plus ethylenediaminetetraacetic acid every 7-10 days. Cells were used at passages 7-14 for all experiments. The medium was changed every other day with either control media or control media supplemented with $10 \mu \mathrm{g} / \mathrm{mL}$ of insulin for a total of seven days.

Insulin powder was dissolved in $0.01 \mathrm{~N} \mathrm{HCl}$ solution. The stock solution had $2 \mathrm{mg} / \mathrm{mL}$ concentration in $0.01 \mathrm{~N} \mathrm{HCl}$, and working solution had $10 \mu \mathrm{g} / \mathrm{mL}$ in medium. Three groups of cells were subjected to insulin: For one day experiment, $2 \times 10^{5}$ cells; for three days experiment, $1 \times 10^{5}$ cells; and for seven days experiment $5 \times 10^{4}$ cells were plated in $20 \mathrm{~mm}$ dishes and exposed to the different regimens of insulin. Briefly, cells were incubated with insulin in medium for one day, three days, and seven days. Cells were plated in five dishes for each condition. After the experiment, cells were harvested, and total RNA plus protein isolations were performed.

Total RNA was extracted with TRIzol (Invitrogen, Carlsbad, CA, USA, Cat\#15596-018) according to the manufacturer's instructions. Two micrograms of RNA were reverse transcribed with RevertAid M-MuLV Reverse Transcriptase (Thermo Scientific, Waltham, MA, USA, Cat\# EP0441) and random hexamers (Thermo Scientific, Waltham, MA, USA) with random primers according to the manufacturer's instruction (Table 1). Human glyceraldehyde 3-phosphate dehydrogenase (GAPDH) was amplified as a control for the polymerase chain reaction (PCR). Samples lacking reverse transcriptase were amplified as a control for genomic DNA contamination. RNase-free water (Qiagen $\mathrm{GmbH}$, Germany) was used to elute 


\begin{tabular}{|c|c|c|}
\hline \multicolumn{3}{|l|}{ ADAMTS12 } \\
\hline $\begin{array}{l}\text { Forward } \\
\text { Reverse }\end{array}$ & $\begin{array}{l}\text { AGTGGGCAACTGGAGTGAGT } \\
\text { ACATGTGACACTGCGAATCC }\end{array}$ & $67 \mathrm{bp}$ product \\
\hline \multicolumn{3}{|l|}{ GAPDH } \\
\hline $\begin{array}{l}\text { Forward } \\
\text { Reverse }\end{array}$ & $\begin{array}{l}\text { CCTGCACCACCAACTGCTTA } \\
\text { TCTTCTGGGTGGCAGTGATG }\end{array}$ & $108 \mathrm{bp}$ product \\
\hline
\end{tabular}

total RNA from each sample. Ultraviolet-visible spectrophotometry was used to quantify and determine the purity of each sample. Quantitative reverse transcriptase (qRT)-PCR was performed on cDNA samples obtained (Qiagen Rotor-Gene Q RT-PCR, Limburg, Netherlands) as described in a previous report. ${ }^{2}$ Total RNA RT-PCR section uses the intercalating dye $\mathrm{SYBR}^{\circledR}$ green (Thermo Scientific Maxima SYBR ${ }^{\circledR}$ Green/ROX qPCR Master Mix (2X) Cat\#K0221) in the presence of primer pairs. The PCR mixture consisted of $\mathrm{SYBR}^{\circledR}$ Green PCR Master Mix, which includes DNA polymerase, SYBR ${ }^{\circledR}$ Green I Dye, deoxynucleotide triphosphates including deoxyuridine triphosphate, PCR buffer, 10 pmol forward and reverse primers, and cDNA of samples in a total volume of $20 \mu \mathrm{L}$. Housekeeping gene, GAPDH, was amplified for normalizing the efficiency of cDNA synthesis and the amount of RNA applied. PCR was performed with initial denaturation at $95{ }^{\circ} \mathrm{C}$ for five minutes, followed by amplification for 40 cycles, each cycle consisting of denaturation at $95^{\circ} \mathrm{C}$ for $10 \mathrm{~s}$, annealing at $57{ }^{\circ} \mathrm{C}$ for $30 \mathrm{~s}$, polymerization at $72{ }^{\circ} \mathrm{C}$ for $30 \mathrm{~s}$ and, the last stage, polymerization at $72{ }^{\circ} \mathrm{C}$ for five minutes. The results pertaining to ADAMTS12 were represented as graphics. The bars and error bars represent mean and standard deviations of amplicon concentrations obtained by $\mathrm{PCR}$ reaction.

Anti-ADAMTS12 primary antibodies were purchased from Santa Cruz (Santa Cruz Biotechnology, Inc., CA, USA) and used at a
1:100 dilution. Cross-reactivity was confirmed before the study to agree with that described on the manufacturer's data sheet. After experiment, the cells were washed once with phosphatebuffered saline and then scraped from the plates. Cells were solubilized in $300 \mu \mathrm{L}$ of CelLytic M (SigmaAldrich, St. Louis, MO, USA, Cat\# C2978) with a protease inhibitor mixture. After incubation in a rotator at $4{ }^{\circ} \mathrm{C}$ for 15 minutes, the samples were centrifuged, and the supernatants were collected. The protein concentration of the cell extracts was determined using a protein assay kit (Thermo Scientific Bradford Assay Kit Cat\#23238) and bovine serum albumin as standard. Protein samples were boiled at $95^{\circ} \mathrm{C}$ in Laemmli sample buffer (BioRad Cat\#161-0747) and $\beta$-mercaptoethanol for eight minutes. Ten micrograms of total protein were used for Western blot analysis. Briefly, $10 \mu \mathrm{L}$ of each sample including protein marker (BioRad Precision Plus Protein Western C Standard, Cat\#161-0376) were loaded to Western blot gel (BioRad MiniPROTEAN TGX Stain-Free Gels, 4-15\%, 15-well comb, $15 \mu \mathrm{L}$, Cat\#456-8096) in BioRad 1X Tris/Glycerine/SDS running buffer and run at $250 \mathrm{~V}$ for 20 minutes. After electrophoresis, proteins were transferred onto polyvinylidene difluoride membranes (BioRad Trans-Blot Turbo Transfer Pack, 0.22 $\mu$ M PVDF, Cat\#170-4156) by using transfer system (BioRad Trans-Blot Turbo Transfer System, Singapore). Membranes were blocked for one hour in $2.5 \%$ nonfat dried skim

Table 2. Primary and secondary antibodies used for ADAMTS12 Western blot analyses

\begin{tabular}{lcccc}
\hline Primary antibody & $\begin{array}{c}\text { Primary antibody } \\
\text { concentration }\end{array}$ & $\begin{array}{c}\text { Secondary } \\
\text { antibody }\end{array}$ & $\begin{array}{c}\text { Secondary antibody } \\
\text { concentration }\end{array}$ & Reaction \\
\hline ADAMTS12 & $1 / 1000$ & Goat & $1 / 4000$ & Mouse, rat, human \\
GAPDH & $1 / 10000-1 / 50000$ & Rabbit & $1 / 4000$ & $\begin{array}{c}\text { Human } \\
36\end{array}$ \\
\hline ADAMTS: A disintegrin and metalloproteinase with thrombospondin motifs; GAPDH: Glyceraldehyde 3-phosphate dehydrogenase. & \\
\hline
\end{tabular}


milk in Tris-buffered saline containing 0.05\% Tween 20. The membranes were incubated overnight for 16 hours with primary antiADAMTS12 and anti-GAPDH antibodies (Table 2) diluted in blocking buffer. After washing with Tris-buffered saline with Tween 20 three times for eight minute each at room temperature, the membranes were incubated one hour with the appropriate secondary antibodies (Table 2). Following three successive washes with Trisbuffered saline with Tween 20, immunoreactive bands were visualized using the enhanced chemiluminescence system (BioRad Immun-Star Western C kit) for 90 seconds. Signals were detected with BioRad ChemiDoc MP Imaging System (Singapore), and the densitometry was performed with Image J software (W. Rasband, Research Services Branch, NIMH, National Institutes of Health, Bethesda, MD) and normalized to the signal intensity of GAPDH for equal protein loading control of each sample in each experiment. This quantification was performed with the linear range of the standard
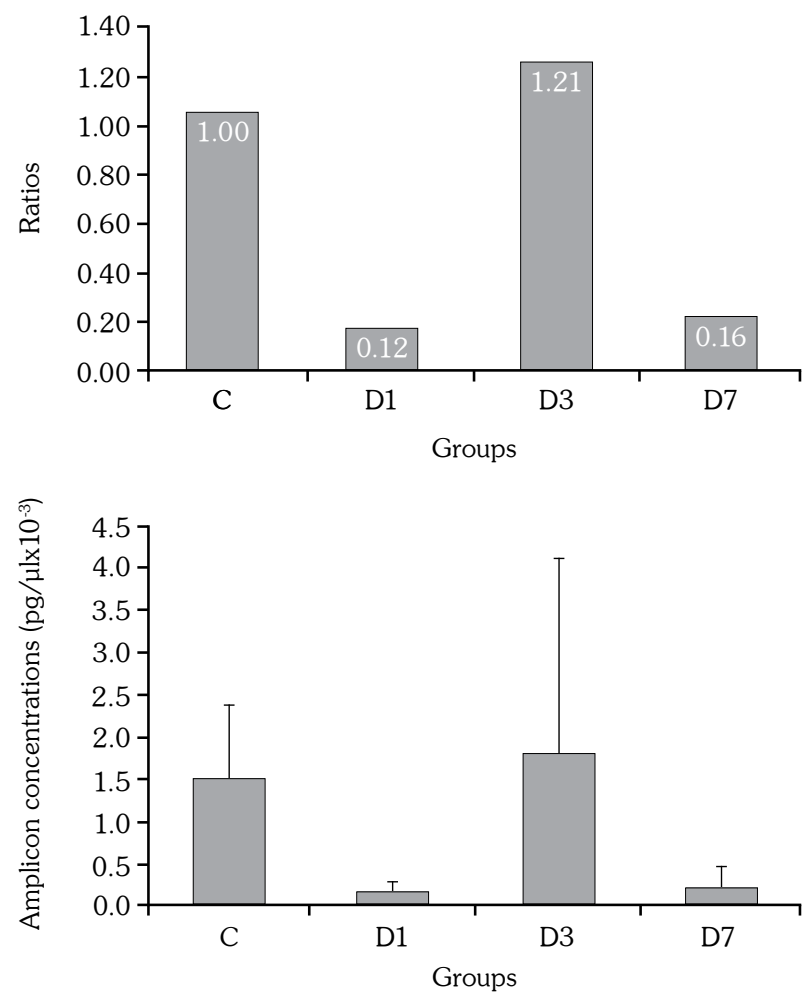

Figure 1. A disintegrin-like and metalloproteinase with thrombospondin motifs12/glyceraldehyde 3-phosphate dehydrogenase ratios and amplicon concentrations according to Quantitative reverse transcriptase-polymerase chain reaction results. curve defined by the standard sample, GAPDH, for all densitometry analysis.

\section{Statistical analysis}

Statistical Package for the Social Sciences (SPSS Inc., Chicago, IL, USA) version 16.0 was used for statistical assessment. Nonparametric Kruskal Wallis test was applied. The relationships between the variables were tested by MannWhitney $\mathrm{U}$ test. $\mathrm{P}<0.05$ was accepted as significant.

\section{RESULTS}

The effects of insulin on ADAMTS12 has been investigated at gene and protein levels. ADAMTS12 expression was significantly lower in the groups applied insulin medium for one day and seven day periods $(p=0.008$ and $p=0.008$, respectively) compared to the control group. No significant difference was detected between the group treated with insulin medium for three days and the control group $(p=0.548)$. Gene expression was significantly higher in the group treated with insulin for three days compared with the group kept in insulin-medium for one day $(p=0.016)$ (Figure 1).

Protein levels of the groups exposed to insulin medium for one, three and seven day periods were lower than the control group (Figure 2).

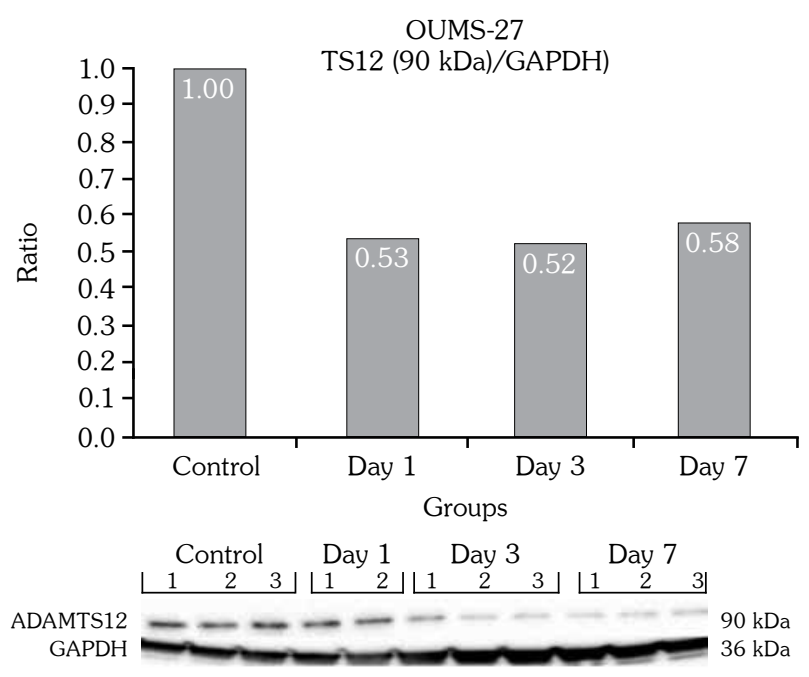

Figure 2. Results of Western blot analysis for ADAMTS12. ADAMTS: A disintegrin-like and metalloproteinase with thrombospondin motifs; GAPDH: Glyceraldehyde 3-phosphate dehydrogenase. 


\section{DISCUSSION}

Extracellular matrix (ECM) surrounds cells, providing mechanical support to cells and also mediating their functionality. The proteoglycans in ECM serve as a bridge between cells and matrix, and contributes to construction of ECM by affecting collagens. The interaction between cells and ECM is important for normal development and functionality of the organism. The modulation of cell-matrix interaction is provided by the proteolytic systems that contribute to hydrolysis of the components in $\mathrm{ECM}$. Therefore, any reduction or increase in proteolytic activity is critical with respect to pathophysiology of several diseases. ${ }^{28}$ Matrix metalloproteinases and ADAMTSs are two major protease families that play role in breakdown of ECM. ${ }^{4}$ The breakdown of ECM by ADAMTSs deteriorates cell-matrix interaction, and causes formation of a new matrix with problematic fibrillar network and changed biomechanical properties. ${ }^{29}$ In this study, we also investigated the changes at levels of gene expression of ADAMTS12 and protein which may play role in destruction of the cartilage tissue.

The pathophysiology of arthritic joint destruction involves proteolytic breakdown of cartilage tissue by matrix metalloproteinases and ADAMTSs. The breakdown of aggrecan, in particular, which is included in the extracellular matrix, is critical in articular damage. ${ }^{2-4}$ Osteoarthritis and rheumatoid arthritis are among joint disorders which involve cartilage damage. Osteoarthritis is a disorder that occurs due to impaired balance between breakdown and repair in the articular cartilage, and characterized with cartilage degeneration, synovitis, and osteophytes. ${ }^{30}$ Rheumatoid arthritis, another disorder affecting joints, is a chronic and systemic inflammatory disease, and characterized with inflammatory proliferation of synovial tissues, breakdown of bone and cartilages, and disabilities. ${ }^{31}$ Impaired structural integrity of articular cartilage is commonly observed in diabetic patients as well as disorders such as osteoarthritis and rheumatoid arthritis, and changes are observed in the amounts of proteoglycans in the intervertebral discs. Increased cartilage damage and delayed bone fracture healing may be also monitored in diabetes. ${ }^{24-26}$ There are ongoing studies on molecular mechanism of cartilage damage in diabetes. Levels of receptor activator of nuclear factor- $\kappa \mathrm{B}$ ligand and tumor necrosis factor-alpha (TNF- $\alpha$ ) which cause resorption of the mineralized cartilage tissue increase in diabetes. ${ }^{32,33}$ Insulin therapy provides integrity of the cartilage tissue by decreasing levels of receptor activator of nuclear factor- $\kappa \mathrm{B}$ ligand and TNF- $\alpha .{ }^{34}$ Also, levels of ADAMTS4 which increase in diabetic rats and show aggrecanase activities are reduced when insulin is applied. ${ }^{34}$ Cai et al. ${ }^{23}$ have detected that the amount of proteoglycans increases depending on dosage when insulin is added to chondrocyte medium of primary porcines. In the study, insulin eliminated the negative effect of IL-1 alpha on synthesis of proteoglycans. On the other hand, insulin reduced levels of breakdown products due to aggrecanases in the mediums with and without IL-1 alpha. In the same study, insulin increased the amounts of proteoglycans in Dunkin Hartley guinea pigs with different levels of osteoarthritis and different ages. The synthesis of proteoglycans decreased inversely proportional to the severity of diabetes in streptozotocin-induced diabetic rats; however, it increased when insulin was applied. When insulin and IGF-1 were applied to cartilage tissues of patients who underwent joint replacement, matrix synthesis increased due to both administrations; however, a higher increase was detected in the groups treated with insulin. Evaluation of above data suggests that insulin can be used as an important agent in treatment of different stages of osteoarthritis. ${ }^{23}$ In another study, Kayal et al. ${ }^{34}$ have investigated the effects of diabetes and insulin therapy on cartilage tissue on a diabetic rat model. The cartilage tissue in the normoglycemic group, which received insulin therapy, was 1.6-fold higher than the diabetic group. Also, we have investigated the effect of insulin on the cells with chondrocytic properties. We analyzed how insulin changed levels of ADAMTS12 which is associated with cartilage tissue and synthesized by chondrocytes. Following administration of insulin, gene expression of ADAMTS12 decreased in the first and seventh days whereas amounts of protein decreased in the first, third and seventh days. These results have suggested that ADAMTS12, with probably high levels in diabetes, and which may contribute to formation of cartilage, may be reduced with insulin therapy. 
ADAMTS12, being a member of ADAMTSs family, is secreted from the surface of chondrocytes, it binds to components of ECM, and inhibits differentiation of chondrocytes. ${ }^{8,35}$ In the cells that ADAMTS12 is overexpressed; all of the early (collagen II and Sox9) and late (collagen $\mathrm{X}$ ) chondrogenic markers are repressed. ${ }^{35} \mathrm{v}-\mathrm{MAF}$ avian musculoaponeurotic fibrosarcoma oncogene homolog gene regulates transcription of ADAMTS12 gene by binding to its "Maf recognition element" sequence. $^{36}$ ADAMTS12, whose expression is regulated by $\mathrm{v}$-MAF avian musculoaponeurotic fibrosarcoma oncogene homolog gene, affects chondrogenic differentiation and hypertrophy negatively. However, normal development of cartilage requires appropriate expression of ADAMTS12. Abnormal level or dysfunctionality of ADAMTS12 may cause dysregulation and arthritis in the cartilage tissue. ${ }^{31}$ ADAMTS12 may contribute to development of osteoarthritis by increasing breakdown of cartilage oligomeric matrix protein. ${ }^{31}$ Oligomeric matrix protein is one of the non-collagenous components of the cartilage tissue and contributes to stabilization of cartilage ECM due to its interaction with collagen types II and IX, aggrecan, and fibronectin. ${ }^{37-39}$ TNF- $\alpha$ causes increased breakdown of oligomeric matrix protein by induction of ADAMTS12. ${ }^{31}$ Some studies in the literature have shown increased amounts of ADAMTS12 in the cartilage and synovial membranes of the patients with osteoarthritis and rheumatoid arthritis. ${ }^{18,40}$ The destructive effect of ADAMTS12 on aggrecan has been also detected. ${ }^{41}$ In our study, both gene expressions and amounts of protein for ADAMTS12 were lower in the insulin-applied group compared with the control group. Considering negative effects of ADAMTS12 on chondrogenic differentiation and hypertrophy, it has been concluded that this effect of insulin may contribute positively to recovery of cartilage tissue. The effect of insulin on ADAMTS12 may be mediated by musculoaponeurotic fibrosarcoma oncogene homolog. Insulin may have shown this effect also by leading to reduction in amount of TNF- $\alpha$.

The breakdown in the cartilage tissue is one of the earliest findings of osteoarthritis, and use of agents for preventing this breakdown and/or synthesis of matrix components is important in preventing progression of the disease and for treatment. ${ }^{42,43}$ The excessive amounts of nitric oxide and IL-1 cause cartilage damage; therefore, reducing or antagonizing amounts of these biomolecules is important in preventing cartilage damage. ${ }^{44,45}$ Growth factors are required for repair of cartilage tissue. Bone morphogenetic protein, IGF, and transforming growth factor beta are required for in vivo and ex vivo repair and growth of cartilage tissue. ${ }^{42,43}$ IGF-1 deficiency may cause osteoarthritis, and level of IGF-1 is high in patients with osteoarthritis. ${ }^{43,46}$ In the study of Cai et al., ${ }^{23}$ decreased amount of IL-1 due to insulin therapy has supported the thesis suggesting that insulin may be useful in treatment of arthritis. Evaluation of growth factors, inflammatory indicators, and effects of insulin on ADAMTS12 at levels of gene expression and amounts of protein reveal that insulin may contribute to recovery of cartilage tissue. Insulin may be helpful as a therapeutic agent in several stages of articular damage.

In conclusion, insulin reduces the amount of ADAMTS12 which causes delayed recovery of cartilage tissue in the OUMS-27 cell lines, which were used in our study for their chondrocytic properties. This reduction may contribute to recovery of cartilage tissue.

\section{Declaration of conflicting interests}

The authors declared no conflicts of interest with respect to the authorship and/or publication of this article.

\section{Funding}

The authors received no financial support for the research and/or authorship of this article.

\section{REFERENCES}

1. Close DR. Matrix metalloproteinase inhibitors in rheumatic diseases. Ann Rheum Dis 2001;60:62-7.

2. Demircan K, Hirohata S, Nishida K, Hatipoglu OF, Oohashi T, Yonezawa T, et al. ADAMTS-9 is synergistically induced by interleukin-1beta and tumor necrosis factor alpha in OUMS-27 chondrosarcoma cells and in human chondrocytes. Arthritis Rheumatol 2005;52:1451-60.

3. Nagase H, Kashiwagi M. Aggrecanases and cartilage matrix degradation. Arthritis Res Ther 2003;5:94-103.

4. Koshy PJ, Lundy CJ, Rowan AD, Porter S, Edwards $\mathrm{DR}$, Hogan $\mathrm{A}$, et al. The modulation of matrix metalloproteinase and ADAM gene expression in 
human chondrocytes by interleukin-1 and oncostatin $\mathrm{M}$ : a time-course study using real-time quantitative reverse transcription-polymerase chain reaction. Arthritis Rheumatol 2002;46:961-7.

5. Apte SS. A disintegrin-like and metalloprotease (reprolysin type) with thrombospondin type 1 motifs: the ADAMTS family. Int J Biochem Cell Biol 2004;36:981-5.

6. Melching LI, Fisher WD, Lee ER, Mort JS, Roughley PJ. The cleavage of biglycan by aggrecanases. Osteoarthritis Cartilage 2006;14:1147-54.

7. Cal S, Arguelles JM, Fernandez PL, Lopez-Otin C. Identification, characterization, and intracellular processing of ADAM-TS12, a novel human disintegrin with a complex structural organization involving multiple thrombospondin-1 repeats. J Biol Chem 2001;276:17932-40.

8. Liu CJ, Kong W, Xu K, Luan Y, Ilalov K, Sehgal $\mathrm{B}$, et al. ADAMTS-12 associates with and degrades cartilage oligomeric matrix protein. $\mathrm{J}$ Biol Chem 2006;281:15800-8.

9. Kurz T, Hoffjan S, Hayes MG, Schneider D, Nicolae R, Heinzmann A, et al. Fine mapping and positional candidate studies on chromosome 5 p13 identify multiple asthma susceptibility loci. J Allergy Clin Immunol 2006;118:396-402.

10. Lin EA, Liu CJ. The role of ADAMTSs in arthritis. Protein Cell 2010;1:33-47.

11. Zhang Q, Huang M, Wang X, Xu X, Ni M, Wang Y. Negative effects of ADAMTS-7 and ADAMTS-12 on endplate cartilage differentiation. J Orthop Res 2012;30:1238-43.

12. Yu H, Zhu Y. Expression of ADAMTS-7 and ADAMTS-12 in the nucleus pulposus during degeneration of rat caudal intervetebral disc. J Vet Med Sci 2012;74:9-15.

13. Moncada-Pazos A, Obaya AJ, Llamazares M, Heljasvaara R, Suarez MF, Colado E, et al. ADAMTS-12 metalloprotease is necessary for normal inflammatory response. $\mathrm{J}$ Biol Chem 2012;287:39554-63.

14. Paulissen G, El Hour M, Rocks N, Gueders MM, Bureau F, Foidart JM, et al. Control of allergeninduced inflammation and hyperresponsiveness by the metalloproteinase ADAMTS-12. J Immunol 2012;189:4135-43.

15. Moncada-Pazos A, Obaya AJ, Fraga MF, Viloria CG, Capella G, Gausachs M, et al. The ADAMTS12 metalloprotease gene is epigenetically silenced in tumor cells and transcriptionally activated in the stroma during progression of colon cancer. J Cell Sci 2009;122:2906-13.

16. El Hour M, Moncada-Pazos A, Blacher S, Masset A, Cal S, Berndt S, et al. Higher sensitivity of Adamts12deficient mice to tumor growth and angiogenesis. Oncogene 2010;29:3025-32.

17. Wang D, Zhu T, Zhang FB, He C. Expression of ADAMTS12 in colorectal cancer-associated stroma prevents cancer development and is a good prognostic indicator of colorectal cancer. Dig Dis Sci 2011;56:3281-7.

18. Kevorkian L, Young DA, Darrah C, Donell ST, Shepstone L, Porter S, et al. Expression profiling of metalloproteinases and their inhibitors in cartilage. Arthritis Rheumatol 2004;50:131-41.

19. Liu CJ. The role of ADAMTS-7 and ADAMTS-12 in the pathogenesis of arthritis. Nat Clin Pract Rheumatol 2009;5:38-45.

20. Hajek AS, Solursh M. Stimulation of growth and mucopolysaccharide synthesis by insulin treatment of chick embryo chondrocytes in cell culture. Gen Comp Endocrinol 1975;25:432-46.

21. Stevens RL, Hascall VC. Characterization of proteoglycans synthesized by rat chondrosarcoma chondrocytes treated with multiplication-stimulating activity and insulin. J Biol Chem 1981;256:2053-8.

22. Sadick MD, Intintoli A, Quarmby V, McCoy A, Canova-Davis E, Ling $\mathrm{V}$. Kinase receptor activation (KIRA): a rapid and accurate alternative to end-point bioassays. J Pharm Biomed Anal 1999;19:883-91.

23. Cai L, Okumu FW, Cleland JL, Beresini M, Hogue D, Lin Z, et al. A slow release formulation of insulin as a treatment for osteoarthritis. Osteoarthritis Cartilage 2002;10:692-706.

24. Kayal RA, Tsatsas D, Bauer MA, Allen B, Al-Sebaei MO, Kakar S, et al. Diminished bone formation during diabetic fracture healing is related to the premature resorption of cartilage associated with increased osteoclast activity. J Bone Miner Res 2007;22:560-8.

25. Athanasiou KA, Fleischli JG, Bosma J, Laughlin TJ, Zhu CF, Agrawal CM, et al. Effects of diabetes mellitus on the biomechanical properties of human ankle cartilage. Clin Orthop Relat Res 1999;368:182-9.

26. Robinson D, Mirovsky Y, Halperin N, Evron Z, Nevo $Z$. Changes in proteoglycans of intervertebral disc in diabetic patients. A possible cause of increased back pain. Spine 1998;23:849-55.

27. Kunisada T, Miyazaki M, Mihara K, Gao C, Kawai A, Inoue $\mathrm{H}$, et al. A new human chondrosarcoma cell line (OUMS-27) that maintains chondrocytic differentiation. Int J Cancer 1998;77:854-9.

28. Mandal M, Mandal A, Das S, Chakraborti T, Sajal C. Clinical implications of matrix metalloproteinases. Mol Cell Biochem 2003;252:305-29.

29. Stanton H, Melrose J, Little CB, Fosang AJ. Proteoglycan degradation by the ADAMTS family of proteinases. Biochim Biophys Acta 2011;1812:1616-29.

30. Lotz MK, Kraus VB. New developments in osteoarthritis. Posttraumatic osteoarthritis: pathogenesis and pharmacological treatment options. Arthritis Res Ther 2010;12:211.

31. Wei J, Richbourgh B, Jia T, Liu C. ADAMTS-12: a multifaced metalloproteinase in arthritis and inflammation. Mediators Inflamm 2014;2014:649718. 
32. Kon T, Cho TJ, Aizawa T, Yamazaki M, Nooh N, Graves D, et al. Expression of osteoprotegerin, receptor activator of NF-kappaB ligand (osteoprotegerin ligand) and related proinflammatory cytokines during fracture healing. J Bone Miner Res 2001;16:1004-14.

33. Barnes GL, Kostenuik PJ, Gerstenfeld LC, Einhorn TA. Growth factor regulation of fracture repair. J Bone Miner Res 1999;14:1805-15.

34. Kayal RA, Alblowi J, McKenzie E, Krothapalli N, Silkman L, Gerstenfeld L, et al. Diabetes causes the accelerated loss of cartilage during fracture repair which is reversed by insulin treatment. Bone 2009;44:357-63.

35. Bai XH, Wang DW, Luan Y, Yu XP, Liu CJ. Regulation of chondrocyte differentiation by ADAMTS-12 metalloproteinase depends on its enzymatic activity. Cell Mol Life Sci 2009;66:667-80.

36. Hong E, Yik J, Amanatullah DF, Di Cesare PE, Haudenschild DR. c-Maf Transcription factor regulates ADAMTS-12 expression in human chondrogenic cells. Cartilage 2013;4:177-86.

37. Jeon SY, Park JS, Yang HN, Woo DG, Park KH. Aggrecan- and COMP-loaded poly-(lactic-coglycolic acid) nanoparticles stimulate chondrogenic differentiation of human mesenchymal stem cells. Stem Cells Dev 2014;23:305-17.

38. Hoch JM, Mattacola CG, Medina McKeon JM, Howard JS, Lattermann C. Serum cartilage oligomeric matrix protein (sCOMP) is elevated in patients with knee osteoarthritis: a systematic review and meta-analysis.
Osteoarthritis Cartilage 2011;19:1396-404.

39. Posey KL, Hecht JT. The role of cartilage oligomeric matrix protein (COMP) in skeletal disease. Curr Drug Targets 2008;9:869-77.

40. Davidson RK, Waters JG, Kevorkian L, Darrah C, Cooper A, Donell ST, et al. Expression profiling of metalloproteinases and their inhibitors in synovium and cartilage. Arthritis Res Ther 2006;8:R124.

41. Llamazares M, Obaya AJ, Moncada-Pazos A, Heljasvaara R, Espada J, Lopez-Otin C, et al. The ADAMTS12 metalloproteinase exhibits antitumorigenic properties through modulation of the Ras-dependent ERK signalling pathway. J Cell Sci 2007;120:3544-52.

42. Frenkel SR, Di Cesare PE. Degradation and repair of articular cartilage. Front Biosci 1999;4:D671-685.

43. O'Connor WJ, Botti T, Khan SN, Lane JM. The use of growth factors in cartilage repair. Orthop Clin North Am 2000;31:399-410.

44. Arend WP, Malyak M, Guthridge CJ, Gabay C. Interleukin-1 receptor antagonist: role in biology. Ann Rev Immunol 1998;16:27-55.

45. Amin AR, Abramson SB. The role of nitric oxide in articular cartilage breakdown in osteoarthritis. Curr Opin Rheumatol 1998;10:263-8.

46. Martel-Pelletier J, Di Battista JA, Lajeunesse D, Pelletier JP. IGF/IGFBP axis in cartilage and bone in osteoarthritis pathogenesis. Inflamm Res 1998;47:90-100. 